Research Paper:

\title{
The Prevalence of Drug-Drug Interaction and Inappro- priate Drug Prescription Among the Elderly in Kashan
}

\author{
Mansour Dianati ${ }^{1}$, Neda Mirbagher Ajorpaz ${ }^{2}$,, Mohammad Sajjad Lotfi $^{3 *}$ (D), Maryam Najarzadeh (D) $^{4}$
}

1. Department of Medical-Surgical Nursing, School of Nursing and Midwifery, Kashan University of Medical Sciences, Kashan, Iran 2. Department of Nursing and Midwifery, Autoimmune Diseases Research Center, Kashan University of Medical Sciences, Kashan, Iran. 3. Iranian Research Center on Ageing, University of Social Welfare and Rehabilitation Sciences, Tehran, Iran.

4. Registration Center of Adverse Drug Reaction, Kashan University of Medical Sciences, Kashan, Iran.

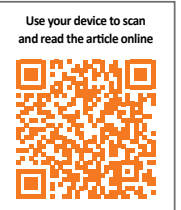

Cftration: Dianati, M., et al. 2019. The Prevalence of Drug-Drug Interaction and Inappropriate Drug Prescription Among the Elderly in Kashan. Journal of Client-Centered Nursing Care, 5(3), pp. 183-192. https://doi.org/10.32598/JCCNC.5.3.183

doi) https://doi.org/10.32598/JCCNC.5.3.183

(c) (1) (5)

Article info:

Received: 04 Feb 2019

Accepted: 25 Jun 2019

Published: 01 Aug 2019

Keywords:

Elderly, Drug interaction, Inappropriate drug

\section{A B S T RA C T}

Background: Drug-Drug Interaction (DDI) among the elderly is one of the major healthcare challenges worldwide. The present study assessed the rates of DDI and inappropriate drug prescription among the elderly in Kashan City, Iran.

Methods: This descriptive-analytical study was designed, conducted, and reported according to the guideline of Strengthening the Reporting of Observational Studies in Epidemiology (STROBE). A random sample of 368 elderly who lived in Kashan City, Iran, was selected through cluster sampling technique. Data collection tools were a demographic questionnaire and a drug checklist. The obtained data were analyzed by the Chi-squared test, logistic regression analysis, and Odds Ratio (OR) in SPSS.

Results: In total, 308 (88\%) participants used at least one drug. The Mean \pm SD scores of daily consumed drugs and the number of inappropriate drugs taken daily by the study participants were $6.21 \pm 3.52$ and $0.28 \pm 0.62$, respectively. Most of the study participants were taking more than two drugs $(n=267,86.68 \%$ ) and more than four drugs $(n=200,64.9 \%)$ per day. The OR of DDI among the study participants who were taking $\geq 2$ drugs per day was 2.49 times greater than those who were taking one or two drugs $(\mathrm{OR}=2.49,95 \%$ confidence interval $=1.20-5.18)$. The most frequent DDIs were between non-steroidal anti-inflammatory drugs and beta-blocker agents $(n=84$, $18.22 \%)$ and between non-steroidal anti-inflammatory drugs and nitrates $(n=46,9.9 \%)$.

Conclusion: The rate of inappropriate drug use among the elderly living in Kashan, Iran, is low, however, polypharmacy and DDIs are highly prevalent among them. To reduce the rates of DDI and polypharmacy, educational programs for different healthcare providers are required to improve their knowledge. Moreover, further studies are needed to assess the effects of polypharmacy and DDI preventive measures, like drug history cards.

\section{* Corresponding Author:}

Mohammad Sajjad Lotfi, PhD.

Address: Iranian Research Center on Ageing, University of Social Welfare and Rehabilitation Sciences, Tehran, Iran

Tel: +98 (939) 0315269

E-mail: sajjad.lotfi@yahoo.com 


\section{Highlights}

- Drug-Drug Interaction (DDI) is highly prevalent among the global elderly population.

- Patients and their family members require adequate knowledge about pharmacodynamics and pharmacokinetics of drugs to prevent DDI or reduce its risk.

- The present findings highlight the necessity of running educational programs for different healthcare providers to improve their knowledge about DDI and polypharmacy.

\section{Plain Language Summary}

This study assessed the rates of inappropriate drug prescription among the elderly in Kashan City, Iran. The study findings revealed that $>85 \%$ of study participants were taking at least one drug. Furthermore, the study participants were taking $>6$ drugs per day, on average. Prescribing inappropriate drugs for the elderly could cause them different life-threatening problems, such as drug toxicity, confusion, falls, and pulmonary aspiration.

\section{Introduction}

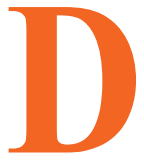

rug-Drug Interaction (DDI) among older adults is one of the major healthcare challenges worldwide (Gujjarlamudi 2016). DDI is defined as the effects of two or more drugs on each other, resulting in the increased effectiveness or toxicity of them (SánchezFidalgo et al. 2017). DDI is highly prevalent among the global elderly population, with different prevalence rates in different countries from 6\% in Brazil (Obreli-Neto et al. 2012) and $8 \%$ in India (Kashyap et al. 2013) to $25.8 \%$ in South Africa (van Heerden et al. 2018) and 58.3\% in Germany (Hoffmann et al. 2011).

DDI is affected by numerous factors (Alomar 2014), i.e. classified into two main categories, namely physiological and pathological factors (Fillit, Rockwood \& Young 2016; Halter et al. 2016). Age-related altered physiological capacity is the most significant physiological factor affecting DDI among the elderly (Kinirons \& O'mahony 2004). With age, the physiological functional capacities of drug-metabolizing and excretory organs, such as liver and kidney are reduced; therefore, the body is no longer able to effectively excrete active metabolites of drugs (Fillit, Rockwood \& Young 2016; (Kinirons \& O'mahony 2004).

The reduced physiological capacity of the body can also lead to pathological consequences and put the elderly at risk for various illnesses, particularly chronic illnesses (Fillit, Rockwood \& Young 2016; Halter et al. 2016). Therefore, the elderly might simultaneously suffer from different illnesses, i.e. technically recognized as comorbidity. Comorbidity necessitates applying multiple and complex treatment regimens (Nobili, Garattini, \& Mannucci 2011).

Studies in Iran suggested that older people in Isfahan and Gonabad cities used at least 3 and 4 (Delshad Noghabi et al. 2014) drugs per day, respectively. This value was reported to be 6.7 in Germany, 9.1 in India, 2.7 in Brazil (Secoli et al. 2010), and 5.4 in Nigeria (Yusuff \& Okoh, 2015).

The accumulation of active metabolites of drugs in one's body along with polypharmacy and inappropriate drug use increase the risk of DDI and drug side effects (Fillit, Rockwood \& Young 2016), and can lead to frequent hospitalizations, cognitive problems, fall, weakness, and osteoporosis Gujjarlamudi 2016). Each of these conditions can negatively affect personal, familial, and socioeconomic aspects of the elderly's life. They could also impose additional burdens on support, healthcare, insurance, and social systems (Fillit, Rockwood \& Young 2016; Halter et al. 2016).

Given the great vulnerability of older people to polypharmacy and drug interactions, the present study assessed the rates of DDI and inappropriate drug prescription among the elderly in Kashan City, Iran.

\section{Materials and Methods}

This descriptive-analytical study was designed, conducted, and reported according to the guideline of Strengthening the Reporting of Observational Studies in Epidemiology (STROBE). 
A random sample of older people living in Kashan City, Iran, was selected through cluster sampling method from August 2016 to May 2018. Kashan is a big city in Isfahan Province with a population of around 350000 people, according to the 2010 census; approximately $10 \%$ of which is constituted by the elderly. There are 21 primary healthcare centers in Kashan which provide healthcare services to $>24000$ elderly. To implement the cluster random sampling method, initially, 10 centers were randomly recruited using a table of random numbers. Then, a random sample of older people's medical records was recruited from each center using a table of random numbers. The number of records selected from each center was proportionate to the total number of records in that center. Next, the address of each participant was extracted from their medical records. Finally, a research assistant referred to each address and collected the data on the intended participant's drug history. If a study participant was not at the address or refused participation, another medical record was randomly selected and substituted. The study inclusion criteria were an age of $\geq 60$, residence in Kashan, no cognitive problem, and consent for participation.

Based on the results of an earlier study in Isfahan, Iran, considering $\mathrm{d}=0.05, \mathrm{P}=27.6$, and a confidence level of 0.95 (i.e. a $Z$ of 1.96), the sample size was estimated to be $\geq 307$. Sample size calculation formula was. To reduce the sampling error associated with cluster sampling, the estimated sample size was multiplied by 1.2 to reach 368 .

Data collection tools were a demographic questionnaire (including age, gender, marital status, financial status, underlying illnesses, and educational status) and a drug checklist. The checklist items consisted of the number and names of the currently used drugs, prescription type (over-the-counter or by a physician), the repetition of previous prescriptions without medical consultation, the number of prescribing physicians, and the number of age-inappropriate drugs. Age-inappropriate drugs were assessed using Beers' Criteria, revised and updated by the American Geriatrics Society. This instrument has several tables in which potentially inappropriate drugs for older people are listed. It is the most commonly used instrument for inappropriate drug assessment.

The content validity of the Persian version of the instrument was qualitatively assessed by 6 nursing doctorates, two pharmacology doctorates, and two internal medicine specialists (10 in total) from Kashan University of Medical Sciences, Kashan, Iran. The inter-rater Kappa coefficient for 4 raters was equal to 0.94 , implying the acceptable reliability of the instrument. Moreover, the internal consistency of the instrument was confirmed with a splithalf correlation coefficient of 0.86 .

SPSS software was employed for data analysis. The normality of the data was examined through the Kolmogorov-Smirnov test. Furthermore, the Chi-squared test was performed to examine the relationship between DDI and demographic characteristics. The logistic regression analysis and Odds Ratios (OR) were also applied to examine the effects of the study variables on DDI incidence. DDI was calculated by a pharmacology doctorate.

\section{Results}

From 368 distributed questionnaires, 18 were excluded due to partial answering, and 350 were analyzed. The study participants were mostly female (52\%), married $(80.8 \%)$, and illiterate $(88.0 \%)$, with the Mean \pm SD age of $70.63 \pm 8.79$ years (Table 1 ).

Only $12 \%(n=42)$ of the study participants reported no medication consumption. The Mean \pm SD values of daily used drugs and inappropriate drugs taken daily by the other $88 \%$ of the participants $(n=308)$ were $6.21 \pm 3.52$ and $0.28 \pm 0.62$, respectively. About $86.68 \%(n=267)$ of the elderly who on drugs were taking more than two drugs per day, and approximately $64.9 \%(n=200)$ were taking $\geq 4$ drugs per day. Figure 1 shows the relative frequency of the number of drugs taken daily by the study participants.

In total, 461 cases of DDI were found among $55.19 \%$ $(n=170)$ of the elderly who were taking $>1$ drug per day. In other words, the DDI rate was equal to 2.71 cases per person. Around $55.53 \%(n=256)$ of DDIs were moderate, $26.24 \%(\mathrm{n}=121)$ were minor, and 18.22 $(n=84)$ were major cases. Figure 2 provides a detailed presentation of DDIs.

DDI was significantly more prevalent among the study participants who were taking $>2$ drugs per day, compared to those who were taking one or two drugs per day $\left(\chi^{2}=31.46 ; \mathrm{P}=0.001\right)$ (Table 2). The odds of DDI among those who were taking $>2$ drugs was 2.49 times greater than that of those who were taking one or two drugs daily $(\mathrm{OR}=2.49 ; 95 \%$ confidence interval $=1.20-5.18)$.

The logistic regression analysis was used to predict the effects of study variables on the odds of DDI. The obtained results revealed that the only significant predictor of DDI was the number of drugs taken daily $(\mathrm{P}=0.019)$ (Table 3 ). 
Table 1. The study participants' demographic characteristics

\begin{tabular}{|c|c|c|c|c|}
\hline & \multirow{2}{*}{ Variables } & \multicolumn{3}{|c|}{ No. (\%) } \\
\hline & & Characteristics & $\begin{array}{c}\text { Elderly Not Taking } \\
\text { Drugs }\end{array}$ & $\begin{array}{l}\text { Elderly Taking } \\
\text { Drugs }\end{array}$ \\
\hline \multirow[b]{2}{*}{ Age (y) } & $60-69$ & $166(47.4)$ & $23(54.8)$ & $143(46.4)$ \\
\hline & $>70$ & $184(52.6)$ & $19(45.2)$ & $165(53.6)$ \\
\hline \multirow{2}{*}{ Gender } & Female & $182(52.0)$ & $12(28.6)$ & $170(52.2)$ \\
\hline & Male & $168(58.0)$ & 30 (71.4) & $138(44.8)$ \\
\hline \multirow{2}{*}{ Marital status } & Single & $67(19.2)$ & $9(21.4)$ & $58(18.8)$ \\
\hline & Married & $283(80.8)$ & $33(78.6)$ & $250(81.2)$ \\
\hline \multirow{2}{*}{ Educational level } & Illiterate and semiliterate & $308(88.0)$ & $30(71.4)$ & $278(90.3)$ \\
\hline & Literate & $42(12.0)$ & $12(28.6)$ & $30(9.7)$ \\
\hline \multirow{2}{*}{ Economic status } & Poor & $283(80.8)$ & $41(97.6)$ & $242(78.57)$ \\
\hline & Moderate to high & $67(19.2)$ & $1(2.4)$ & $66(21.43)$ \\
\hline \multirow{2}{*}{$\begin{array}{l}\text { Affliction by underlying } \\
\text { illnesses }\end{array}$} & No & $27(7.7)$ & $25(59.5)$ & $2(0.6)$ \\
\hline & Yes & $323(92.3)$ & $17(40.5)$ & $306(99.4)$ \\
\hline \multirow{2}{*}{ Number of daily drugs } & $1-2$ & $41(13.3)$ & --- & $41(13.3)$ \\
\hline & More than 2 & $267(86.7)$ & --- & $267(86.7)$ \\
\hline \multirow{2}{*}{$\begin{array}{l}\text { Number of prescribing } \\
\text { physicians }\end{array}$} & $1-2$ & $277(73.7)$ & --- & $277(73.7)$ \\
\hline & More than 2 & $81(26.3)$ & --- & $81(26.3)$ \\
\hline \multirow{2}{*}{ Prescription repetition } & Yes & $62(20.1)$ & --- & $62(20.1)$ \\
\hline & No & 246 (79.9) & --- & 246 (79.9) \\
\hline \multirow{2}{*}{$\begin{array}{l}\text { Awareness of the reason } \\
\text { for taking drugs }\end{array}$} & No & $43(14.0)$ & --- & $43(14.0)$ \\
\hline & Yes & $265(86.0)$ & --- & $265(86.0)$ \\
\hline \multirow{2}{*}{$\begin{array}{c}\text { Use of over-the-counter } \\
\text { drugs }\end{array}$} & Yes & $74(24.0)$ & --- & $74(24.0)$ \\
\hline & No & $234(76.0)$ & --- & $234(76.0)$ \\
\hline \multirow{2}{*}{ Inappropriate drug use } & No & $242(78.6)$ & --- & $242(78.6)$ \\
\hline & Yes & $66(21.4)$ & --- & $66(21.4)$ \\
\hline
\end{tabular}

Client- Centered Nursing Care

The most common DDIs were between Non-Steroidal Anti-Inflammatory Drugs (NSAIDs) and beta-blocker agents $(\mathrm{n}=84 ; 18.22 \%)$, and between NSAIDs and nitrates $(n=46 ; 9.9 \%)$ (Table 4$)$.

\section{Discussion}

This study assessed the rates of DDI and inappropriate drug prescription among the elderly in Kashan City,
Iran. The obtained findings revealed that $>85 \%$ of the study participants were taking at least one drug per day. Similarly, a study in Turkey suggested that $81 \%$ of Turkish older people were taking at least one drug (Gören et al. 2017). Two other studies in Brazil also reported that $80 \%$ of the Brazilian elderly were taking at least one drug (Obreli-Neto et al. 2012). However, this rate in a study in Gonabad, Iran, was calculated as $72 \%$ (Delshad Noghabi et al. 2014). This discrepancy may be because 
Table 2. Factors affecting DDI among the drug-taking elderly group

\begin{tabular}{|c|c|c|c|c|c|}
\hline & & & & & \\
\hline & & & Yes & No & \\
\hline & $60-69$ & $143(46.4)$ & 77 (45.3\%) & 66 (47.8\%) & \\
\hline Age (y) & $>70$ & $165(53.6)$ & 93 (54.7\%) & 72 (52.2\%) & 0.658 \\
\hline & Female & $170(52.2)$ & 98 (57.6\%) & 72 (52.2\%) & \\
\hline Gender & Male & $138(44.8)$ & 72 (42.4\%) & $66(47.8 \%)$ & 0.337 \\
\hline & Single & $58(18.8)$ & $35(20.6 \%)$ & $23(16.7 \%)$ & \\
\hline Marital status & Married & $250(81.2)$ & 135 (79.4\%) & 115 (83.3\%) & 0.381 \\
\hline Educational level & $\begin{array}{l}\text { Illiterate and semiliter- } \\
\text { ate }\end{array}$ & $278(90.3)$ & $153(90.0 \%)$ & $125(90.6 \%)$ & 0.865 \\
\hline & Literate & $30(9.7)$ & 17 (10.0\%) & 13 (9.4\%) & \\
\hline & Poor & $242(78.57)$ & 167 (98.2\%) & 135 (97.8\%) & \\
\hline & Moderate to high & 66 (21.43) & $3(1.8 \%)$ & $3(2.2 \%)$ & (5) \\
\hline Affliction by ill- & No & $2(0.6)$ & $2(1.2 \%)$ & $0(0 \%)$ & \\
\hline nesses & Yes & 306 (99.4) & 168 (98.8\%) & $138(100.0 \%)$ & \\
\hline Number of daily & $1-2$ & $41(13.3)$ & $30(17.6 \%)$ & $11(8.0 \%)$ & \\
\hline & $>2$ & $267(86.7)$ & $140(82.4 \%)$ & 127 (92.0\%) & \\
\hline Number of pre- & $1-2$ & $277(73.7)$ & $127(74.7 \%)$ & 100 (72.5\%) & \\
\hline scrioing physiclans & $>2$ & $81(26.3)$ & $43(25.3 \%)$ & $38(27.5 \%)$ & \\
\hline Prescription repeti- & Yes & $62(20.1)$ & $35(20.6 \%)$ & 27 (19.6\%) & \\
\hline tion & No & 246 (79.9) & 135 (79.4\%) & 111 (80.4\%) & \\
\hline $\begin{array}{l}\text { Awareness of the } \\
\text { reason for taking }\end{array}$ & No & $43(14.0)$ & $23(13.5 \%)$ & 20 (14.5\%) & 0808 \\
\hline drugs & Yes & $265(86.0)$ & 147 (86.5\%) & 118 (85.5\%) & \\
\hline Use of over-the- & Yes & $74(24.0)$ & $41(24.1 \%)$ & $33(23.9 \%)$ & \\
\hline counter drugs & No & $234(76.0)$ & 129 (75.9\%) & 105 (76.1\%) & \\
\hline Inappropriate drug & No & $242(78.6)$ & 134 (78.8\%) & $108(78.3 \%)$ & \\
\hline & Yes & 66 (21.4) & $36(21.2 \%)$ & 30 (21.7\%) & \\
\hline
\end{tabular}

Client- Centered Nursing Care

we assessed older people's present drug history, while that study assessed three-month drug history through the self-report method (Delshad Noghabi et al. 2014); it might have been associated with recall bias and underreporting due to the prevalence of memory impairments among the elderly.
Study findings also revealed that the participants were taking $>6$ drugs per day, on average. This rate was 2.9 and 2.7 in Brazil (Obreli-Neto et al. 2012; Secoli et al. 2010), 3.7 in Isfahan, Iran, 5.4 in Nigeria (Yusuff \& Okoh 2015), 6.7 in Germany (Hoffmann et al. 2011), 8.83 in South Africa (van Heerden et al. 2018), 9.1 in India (Kashyap et al. 2013), and 14 in Turkey (Gören 
Table 3. The regression model for determining the predictors of DDI among the drug-taking elderly group

\begin{tabular}{|c|c|c|c|c|c|}
\hline \multirow{2}{*}{ Variables } & \multirow{2}{*}{ B } & \multirow{2}{*}{ OR } & \multicolumn{2}{|c|}{$95 \% \mathrm{Cl}$} & \multirow{2}{*}{$\mathbf{P}$} \\
\hline & & & Lower & Upper & \\
\hline Age (y) & -0.168 & 0.846 & 0.514 & 1.390 & 0.508 \\
\hline Gender & 0.240 & 1.271 & 0.756 & 2.139 & 0.366 \\
\hline Marital status & 0.168 & 1.183 & 0.614 & 2.278 & 0.616 \\
\hline Educational level & -0.044 & 0.957 & 0.418 & 2.193 & 0.917 \\
\hline Economic status & -0.728 & 0.483 & 0.078 & 3.005 & 0.435 \\
\hline Number of daily drugs & 0.920 & 2.510 & 1.163 & 5.417 & 0.019 \\
\hline Number of prescribing physicians & 0.089 & 1.093 & 0.649 & 1.839 & 0.738 \\
\hline Number of inappropriate drugs & -0.078 & 0.925 & 0.524 & 1.633 & 0.788 \\
\hline Prescription repetition & -0.062 & 0.940 & 0.507 & 1.745 & 0.845 \\
\hline Use of over-the-counter drugs & -0.163 & 0.850 & 0.477 & 1.515 & 0.581 \\
\hline Awareness of the reason for taking drugs & -0.028 & 0.973 & 0.495 & 1.910 & 0.936 \\
\hline Affliction by illnesses & 0.491 & 0.792 & 0.000 & 0.000 & 0.999 \\
\hline
\end{tabular}

Table 4. The type and the frequency of DDIs among the study participants

\begin{tabular}{cc}
\hline DDIs & No. (\%) \\
\hline Beta-blocker agents and NSAIDs & $84(18.22)$ \\
\hline Nitrates and NSAIDs & $46(9.9)$ \\
Glibenclamide and NSAIDs & $39(8.45)$ \\
\hline NSAIDs and NSAIDs & $40(8.67)$ \\
\hline Histamine 2 blockers and NSAIDs & $37(8.02)$ \\
\hline ACEls and NSAIDs & $26(5.63)$ \\
\hline Benzodiazepines and statins & $17(3.68)$ \\
\hline Diuretics and ACEls & $16(3.47)$ \\
\hline Diuretics and NSAIDs & $15(3.25)$ \\
\hline Histamine 2 blockers and Glibenclamide & $12(2.60)$ \\
\hline Calcium channel blockers and statins & $12(2.60)$ \\
\hline Diuretics and Glibenclamide & $11(2.38)$ \\
\hline
\end{tabular}




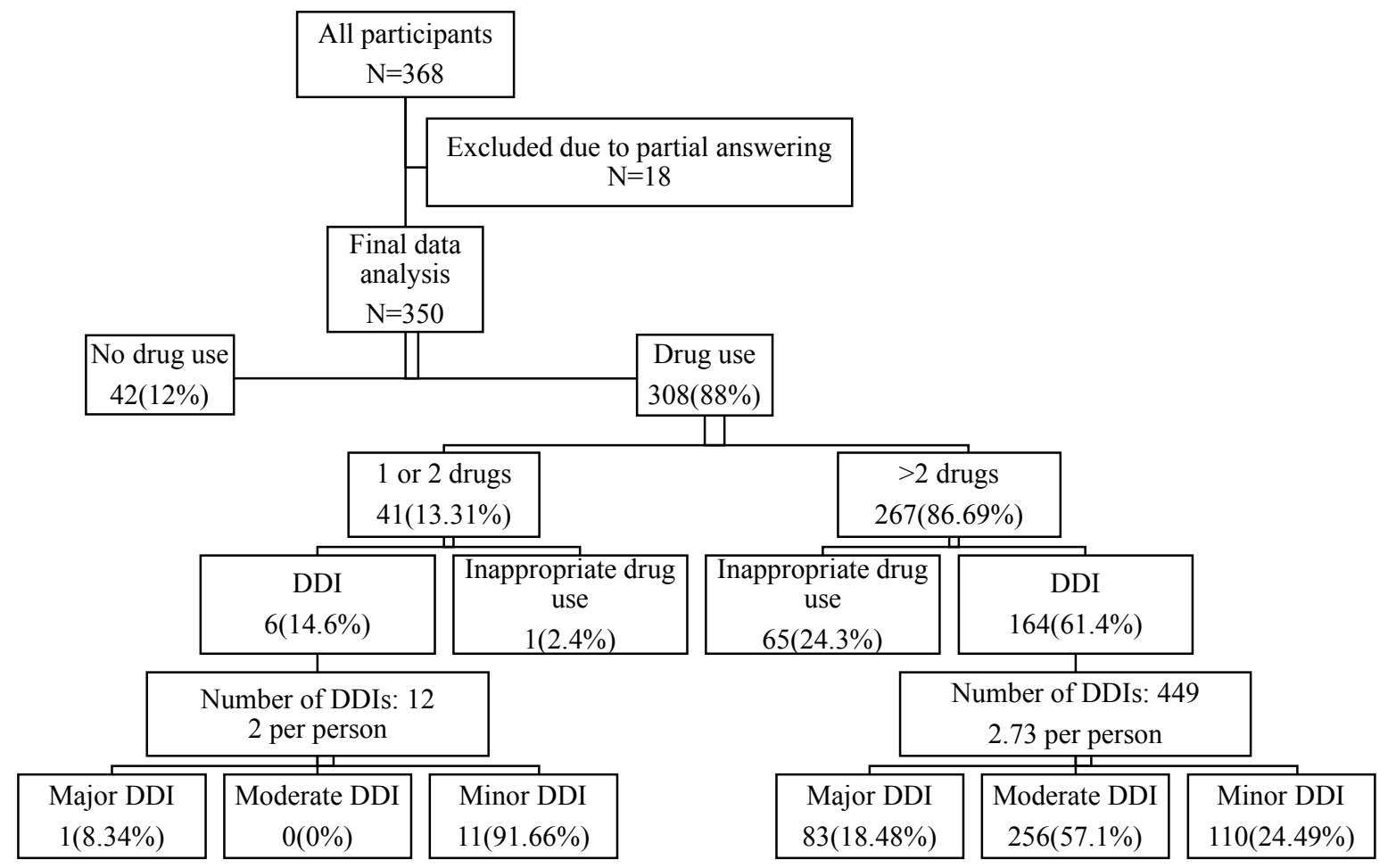

Figure 1. The relative frequency of the number of drugs consumed daily by the study participants

et al. 2017). Such a wide discrepancy among studies regarding the number of drugs taken per day can be attributed to the differences in data collection methods; some studies relied on older people's written prescriptions, some on healthcare system databases, and some of the subjects' self-reported data. Moreover, we found that $>60 \%$ of the elderly were taking $>4$ drugs per day. The same rate was obtained as $56.6 \%$ in Gonabad (Delshad Noghabi et al. 2014). The polypharmacy rate was reported to be $51.5 \%$ in Japan (Komiya et al. 2018), $86.4 \%$ in South Korea (Kim et al. 2014), and 39.4\% in Italy (Scondotto et al. 2018). Such a wide difference in the polypharmacy rate in previous studies may be due to differences in the methods used for polypharmacy assessment (Mortazavi et al. 2016).
Various factors might affect polypharmacy among the elderly, the most important one of which is comorbidity (Salwe, Kalyansundaram \& Bahurupi 2016). With age, physiological capacity is reduced, and the effects of an unhealthy lifestyle are gradually accumulated in the body, putting older adults at great risk for multiple chronic illnesses and subsequent polypharmacy. Besides, comorbidity requires older people to visit different specialists. This, in turn, aggravates polypharmacy (Gujjarlamudi 2016; Fillit, Rockwood \& Young 2016; Halter et al. 2016; Salwe, Kalyansundaram \& Bahurupi 2016).

Another main factor impacting polypharmacy among older people is their use of over-the-counter drugs or the repetition of previous prescriptions. The use of over-the-counter drugs results from factors, such as

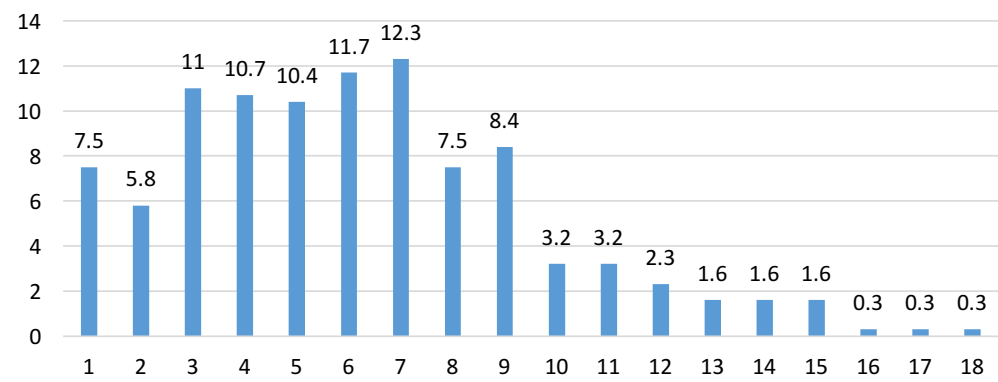

Client- Centered Nursing Care

Figure 2. The frequency of the number of drug-drug interaction, inappropriate drug, and polypharmacy in the study participants 
considering signs and symptoms as minor, easy access to drugs, a history of using drugs, the high costs of medical visits, far distances to medical centers, and limited access to healthcare professionals (Azami-Aghdash et al. 2015). Other potential factors influencing polypharmacy among the elderly may be incoherent insurance systems, not taking previous drugs to physicians at medical visits, the lack of drug history cards, and physicians' failure to take a complete drug history from each elderly during medical visits.

Study findings also indicated that almost $21 \%$ of the study participants were taking at least one inappropriate drug. The mean number of inappropriate drugs taken by them was 0.28 . These values, in an earlier study in Isfahan, Iran, were $27.6 \%$ and 0.32 , respectively. The prevalence rate of taking inappropriate drugs was reported to be $30.3 \%$ in Nigeria (Yusuff \& Okoh, 2015), 23.9\% in Germany (Voigt et al. 2016), and 48.2\% in Japan (Onda et al. 2015). Such data discrepancy could be attributed to the sample differences. For instance, $50 \%$ of the participants in a study in Japan aged $>80$ (Onda et al. 2015).

Another reason behind the difference may be applying different measurement tools for assessing inappropriate drug use. Prescribing inappropriate drugs for older people could generate different life-threatening problems, such as drug toxicity, confusion, falls, and pulmonary aspiration. Inappropriate drug prescription may be due to healthcare providers' lack of knowledge about ageinappropriate medications and their unfamiliarity with tools for assessing inappropriate drugs, like Beers' Criteria. Other reasons include comorbidity-related polypharmacy, patients' requests for certain drugs, physicians' experiences, inaccurate shared experiences by family members', the quality of healthcare providers' professional relationships, and the shortcomings of available prescription-related guidelines (Voigt et al. 2016).

The achieved data also revealed a DDI rate of $>50 \%$ with 2.71 DDIs per elderly. These values in studies conducted in South Africa and Germany were 25.8\% and 0.36 (van Heerden et al. 2018) and 58.3\% and 2.9 (Hoffmann et al. 2011), respectively. A study in Italy also documented 6.4 cases of DDI per elderly (Scondotto et al. 2018). Moreover, studies in Brazil and India reported DDI rates of $6 \%$ (Obreli-Neto et al. 2012) and $8 \%$ (Kashyap et al. 2013), respectively. Factors contributing to DDI among older people could be categorized into three classes of internal, external, and environmental factors (Alomar 2014).
The most significant internal factors are reduced physiological capacity and comorbidity. Decreased drug-metabolizing and excretory capacities of the liver and the kidney could lead to the accumulation of drug metabolites in the body, resulting in the increased risk for DDI (Alomar 2014; Kauffman, Barr \& Moran 2007). External factors, such as fluid consumption, dietary regimen, and cigarette smoking, can also affect drug metabolism and DDI risk. Environmental factors behind DDI also include healthcare providers' unawareness about DDI, inattention to older people's physiological conditions, and multiple drug prescriptions (Alomar 2014; Hoeman 2008).

We also found that the only predictor of DDI was the number of drugs taken daily. Accordingly, older people who were taking $>2$ drugs per day were 2.5 times more at risk for DDI, compared with those taking one or two drugs. Previous studies in South Africa, Italy, Germany, India, and Brazil reported that key factors affecting DDI were age and gender (van Heerden et al. 2018), age and the number of daily drugs (Scondotto et al. 2018), the number of daily drugs and simultaneous affliction by infection and psychiatric disorders (Hoffmann et al. 2011), an age of $>80$, the number of underlying conditions, and the number of daily consumed drugs (Secoli et al. 2010).

Polypharmacy is among the major factors impacting DDI in the elderly (Ahmad et al. 2015). It usually occurs due to visiting various physicians for different underlying conditions. Physicians' unawareness of older people's treatment regimens and previous prescriptions increases the risk of polypharmacy and DDI (Alomar 2014; Zadak et al. 2013). Another factor behind polypharmacy is the patients' repetition of previous prescriptions. Older people in developing countries have low income; therefore, repeat their previous prescriptions to not pay for new medical visits (Azami-Aghdash et al. 2015).

The most common DDIs found in the present study were minor DDIs between beta-blocker agents and nitrates, between NSAIDs and nitrates, and between NSAIDs and glibenclamide. The most important DDIs in a study in South Africa were among amiloride, Angiotensin-Converting Enzyme Inhibitors (ACEIs), and hydrochlorothiazide, between ACEIs and NSAIDs, and between ACEIs and spironolactone (Yusuff \& Okoh, 2015). DDIs in a study in Brazil were mainly between ACEIs and loop or thiazide diuretics, between aspirin and ACEIs, and between NSAIDs and thiazide diuretics (Secoli et al. 2010). Another study reported that the most common DDIs in India were among anticoagulants, clopidogrel, and aspirin, between clopido- 
grel and proton pump inhibitors, and between ramipril and spironolactone (Kashyap et al. 2013). Moreover, a study reported that DDIs between potassium excretion diuretics and NSAIDs, between ACEIs and NSAIDs, and between beta-blocker agents and non-steroidal antiphlogistic drugs were the most common DDIs among the elderly in Germany (Hoffmann et al. 2011).

The differences among studies regarding DDI types could be explained by the differences in the underlying conditions, treatment regimens, and available drug preparations in different countries (Alomar 2014), as well as the differences in DDI assessment methods in different studies. Another major factor influencing DDI among the elderly is using over-the-counter drugs. Individuals usually consider their symptoms minor and use overthe-counter drugs based on their previous experiences (Azami-Aghdash et al. 2015). Using over-the-counter drugs without having adequate knowledge about the pharmacodynamics and pharmacokinetics of drugs may increase DDI risk (Fillit, Rockwood \& Young 2016; Halter et al. 2016). Furthermore, age-related reduced physiological capacity puts older adults at the added risk of DDI. Therefore, besides healthcare providers, patients, and their family members also require adequate knowledge about pharmacodynamics and pharmacokinetics of drugs to prevent DDI or reduce its risk (Kauffman, Barr \& Moran 2007; Hoeman 2008).

The greatest strength of the study was assessing all drugs by trained healthcare specialists. However, the study had some limitations. Drug prescription in Iran is performed using paper-based traditional methods. Therefore, we were unable to assess the study participants' previous prescriptions and instead used a self-report questionnaire. Such a self-report survey might have caused some measurement biases.

The obtained data suggested that although the rate of inappropriate drug use is low among the elderly in Kashan, polypharmacy, and DDI were highly common among them; more than half of them suffered from DDI, chiefly minor DDI. The study findings highlighted the necessity of running educational programs for different healthcare providers to improve their knowledge about DDI and polypharmacy. Given the significant role of polypharmacy in DDI, studies are required to determine factors contributing to polypharmacy. Moreover, exploring the effects of polypharmacy and DDI preventive measures, like drug history cards, could be another area for further investigation.

\section{Ethical Considerations}

\section{Compliance with ethical guidelines}

This study was conducted based on the Declaration of Helsinki on human research and after obtaining permission from the Institutional Review Board, the Health Administration, and the Ethics Committee of Kashan University of Medical Sciences, Kashan, Iran. The study participants and their families were informed about the study and its aims, voluntariness of participation, and confidentiality of data. Their written informed consent was also obtained.

\section{Funding}

This research did not receive any specific grant from funding agencies in the public, commercial, or not-forprofit sectors.

\section{Authors' contributions}

All authors contributed to this article and read and approved the final manuscript for submission.

\section{Conflict of interest}

The authors declared no potential conflicts of interest concerning the research, authorship, and publication of this article.

\section{Acknowledgments}

Authors would like to thank all the elderly and their families who participated in the study, all persons who collaborated with them during data collection, and Kashan University of Medical Sciences, Kashan, Iran, for its financial support.

\section{References}

Ahmad, A., et al. 2015. Evaluation of potential drug-drug interactions in general medicine ward of teaching hospital in southern India. Journal of Clinical and Diagnostic Research, 9(2), p, FC10. [DOI:10.7860/JCDR/2015/11264.5608] [PMID] [PMCID]

Alomar, M. J., 2014. Factors affecting the development of adverse drug reactions. Saudi Pharmaceutical Journal, 22(2), pp. 83-94. [DOI:10.1016/j.jsps.2013.02.003] [PMID] [PMCID]

Azami-Aghdash, S., et al. 2015. Prevalence and cause of selfmedication in iran: A systematic review and meta-analysis article. Iranian Journal of Public Health, 44(12), pp. 1580-93. [PMCID] [PMID] 
Delshad Noghabi, A., et al. 2014. [Irrational use of medicine status in elderly population of Gonabad (Persian)]. Quarterly of the Horizon of Medical Sciences, 19(5), pp: 297-304.

Fillit, H. M., Rockwood, K. \& Young, J.B., 2016. Brocklehurst's textbook of geriatric medicine and gerontology e-book. Amsterdam: Elsevier Health Sciences.

Gören, Z., et al. 2017. Potential drug-drug interactions among prescriptions for elderly patients in primary health care. Turkish Journal of Medical Sciences, 47(1), pp. 47-54. [DOI:10.3906/ sag-1509-89] [PMID]

Gujjarlamudi, H. B., 2016. Polytherapy and drug interactions in elderly. Journal of Mid-Life Health, 7(3), pp. 105-7. [DOI:10.4103/0976-7800.191021] [PMID] [PMCID]

Halter, J. B., et al. 2016. Hazzard's geriatric medicine and gerontology $\left(7^{\text {th }}\right.$ Edition). New York: McGraw-Hill Education.

Hoeman, S. P., 2008. Rehabilitation nursing: Prevention, intervention, and outcomes. Amsterdam: Elsevier Health Sciences.

Hoffmann, W., et al. 2011. Frequency and determinants of potential drug-drug interactions in an elderly population receiving regular home visits by GPs-results of the home medication review in the AGnES-studies. Pharmacoepidemiology and Drug Safety, 20(12), pp. 1311-8. [DOI:10.1002/pds.2224] [PMID]

Kashyap, M., et al. 2013. Drug-drug interactions and their predictors: Results from Indian elderly inpatients. Pharmacy Practice, 11(4), pp. 191-5. [DOI:10.4321/S1886-36552013000400003] [PMID] [PMCID]

Kauffman, T. L., Barr, J. O. \& Moran, M. L. 2007. Geriatric rehabilitation Manual. Amsterdam: Elsevier Health Sciences.

Kim, H. A., et al. 2014. Prevalence and predictors of polypharmacy among Korean elderly. PloS one, 9(6), p. e98043. [DOI:10.1371/journal.pone.0098043] [PMID] [PMCID]

Kinirons, M. \& O'mahony, M., 2004. Drug metabolism and ageing. British Journal of Clinical Pharmacology, 57(5), pp. 540-4. [DOI:10.1111/j.1365-2125.2004.02096.x] [PMID] [PMCID]

Komiya, H., et al. 2018. Factors associated with polypharmacy in elderly homecare patients. Geriatrics \& Gerontology International, 18(1), pp. 33-41. [DOI:10.1111/ggi.13132] [PMID]

Mortazavi, S. S., et al. 2016. Defining polypharmacy in the elderly: A systematic review protocol. BMJ Open, 6(3), pp. e010989. [DOI:10.1136/bmjopen-2015-010989] [PMID] [PMCID]

Nobili, A., Garattini, S. \& Mannucci, P. M., 2011. Multiple diseases and polypharmacy in the elderly: Challenges for the internist of the third millennium. Journal of Comorbidity, 1(1), pp. 28-44. [DOI:10.15256/joc.2011.1.4] [PMID] [PMCID]

Obreli-Neto, P. R., et al. 2012. Adverse drug reactions caused by drug-drug interactions in elderly outpatients: A prospective cohort study. European Journal of Clinical Pharmacology, 68(12), pp. 1667-76. [DOI:10.1007/s00228-012-1309-3] [PMID]

Onda, M., et al. 2015. Identification and prevalence of adverse drug events caused by potentially inappropriate medication in homebound elderly patients: A retrospective study using a nationwide survey in Japan. BMJ Open, 5(8), pp. e007581. [DOI:10.1136/bmjopen-2015-007581] [PMID] [PMCID]

Salwe, K. J., Kalyansundaram, D., \& Bahurupi, Y., 2016. A study on polypharmacy and potential drug-drug interactions among elderly patients admitted in department of medicine of a tertiary care hospital in Puducherry. Journal of Clinical and Diagnostic Research, 10(2), pp. FC06-10. [DOI:10.7860/ JCDR/2016/16284.7273] [PMID] [PMCID]

Sánchez-Fidalgo, S., et al. 2017. Prevalence of drug interactions in elderly patients with multimorbidity in primary care. International Journal of Clinical Pharmacy, 39(2), pp. 343-53. [DOI:10.1007/s11096-017-0439-1] [PMID]

Scondotto, G., et al. 2018. The impact of polypharmacy and drug interactions among the elderly population in Western Sicily, Italy. Aging Clinical and Experimental Research, 30(1), pp. 81-7. [DOI:10.1007/s40520-017-0755-2] [PMID]

Secoli, S. R., et al. 2010. Risk of potential drug-drug interactions among Brazilian elderly. Drugs \& Aging, 27(9), pp. 759-70. [DOI:10.2165/11538460-000000000-00000] [PMID]

van Heerden, J. A., et al. 2018. Prevalence of potentially serious drug-drug interactions among South African elderly private health sector patients using the Mimica Matanović/VlahovićPalčevski protocol. The International Journal of Pharmacy Practice, 26(2), pp. 156-64. [DOI:10.1111/ijpp.12383] [PMID]

Voigt, K., et al. 2016. Why do family doctors prescribe potentially inappropriate medication to elderly patients? BMC Family Practice, 17(1), p. 93. [DOI:10.1186/s12875-016-0482-3] [PMID] [PMCID]

Yusuff, K. B. \& Okoh, C. N. 2015. Frequency, types and factors associated with potentially harmful drug interactions in ambulatory elderly patients in Nigeria. International Journal of Pharmacy Practice, 23(5), pp. 353-6. [DOI:10.1111/ijpp.12167] [PMID]

Zadak, Z., et al. 2013. Polypharmacy and malnutrition. Current Opinion in Clinical Nutrition and Metabolic Care, 16(1), pp. 50-5. [DOI:10.1097/MCO.0b013e32835b612e] [PMID] 